\section{INTRODUCCIÓN Y EPIDEMIOLOGÍA}

Los cálculos urinarios son concreciones macroscópicas de composición variable que se forman o depositan en los cálices, pelvis renal, uréteres o vejiga.

La nefrolitiasis es un problema de salud frecuente cuya prevalencia en Argentina es del 1 a 3\%, aunque algunos autores estiman que llegaría al $12 \%$ al considerar los cálculos asintomáticos. Es un trastorno con alta recurrencia que alcanza el $13 \%$ al año y el $50 \%$ a los diez años del primer episodio.

Predomina en varones (dos a tres veces más común que en mujeres) con un pico de incidencia entre la tercera y quinta década de la vida.Luego de los 50 años se equipara la incidencia de litiasis en ambos sexos. Se postula un efecto protector de los estrógenos y facilitador de la testosterona en la producción de oxalatos a nivel hepático. Las mujeres tienen además niveles superiores de citraturia e inferiores de calciuria.

El $75 \%$ de los cálculos están compuestos por cristales de oxalato de calcio ( $25 \%$ puros, $40 \%$ combinados con fosfato de calcio y $10 \%$ con un núcleo de ácido úrico). En menor proporción se encuentran aquellos cálculos de fosfato de calcio (2 a 9\%) ácido úrico (2 a 9\%) estruvita (magnesio, amonio y fosfato) y cistina.

\section{FACTORES DE RIESGO}

No hay datos concluyentes que prueben que la dieta rica en calcio sea un factor predisponente.

El componente de la dieta con mayor influencia sobre la litogénesis es la proteína animal (carne vacuna, de ave o pescado) que produce una leve acidosis metabólica que incrementa la resorción de calcio óseo (buffer) aumentando la calciuria. También aumenta la uricosuria por el mayor aporte de purinas. Es por ello que la litiasis renal es más frecuente en las poblaciones de alto nivel socioeconómico y en países industrializados.

La baja ingesta de líquidos aumenta el riesgo de desarrollar cálculos, especialmente con diuresis menores a un litro por día. Los aumentos estacionales de temperatura disminuyen el volumen urinario, lo que favorece la precipitación de cristales.Así es más frecuente la incidencia en los meses de verano y en zonas tropicales. Más aun, con la exposición al sol aumenta la síntesis de vitamina $\mathrm{D}$, lo que incrementa la absorción de calcio del tubo digestivo.

\section{PATOGENIA}

La formación de un cálculo requiere de un núcleo y de un medio urinario que favorezca la precipitación. Cuanto mayor sea la saturación de la orina tanto mayor será la tendencia a la formación del núcleo y el crecimiento de cristales.Por ejemplo, la orina normal suele estar sobresaturada de oxalato de calcio, pero no de ácido úrico, cistina o estruvita.Ciertas condiciones como la hipercalciuria y la hiperoxaluria pueden elevar la sobresaturación de oxalato de calcio en la orina y formar los cristales.

El bajo $\mathrm{pH}$ en orina debido a causas hereditarias o enfermedades intestinales facilita la precipitación de ácido úrico, mientras que el $\mathrm{pH}$ elevado en orina debido a álcalis, drogas o acidosis tubular renal predispone a la precipitación de fosfato de calcio y estruvita. Hay sustancias que actúan como catalizadores. El ejemplo típico es el ácido úrico que favorece la precipitación del oxalato de calcio. El calcio y el oxalato son facilitadores de la cristalización. Los inhibidores de la cristalización (magnesio, citrato) y las propiedades específicas de la superficie urotelial pueden explicar el bajo porcentaje de cálculos de oxalato de calcio a pesar de que la sobresaturación de esta sal en la orina es casi universal, aún en pacientes que no desarrollan litiasis urinaria.

\section{FORMAS DE PRESENTACION CLINICA}

La presentación clínica puede variar desde el hallazgo de un cálculo en un paciente asintomático descubierto en un estudio de imágenes, hasta el cólico renal.Puede descubrirse la litiasis frente al estudio de pacientes con hematuria, infecciones urinarias recurrentes o persistentes y síntomas menos específicos (dolor lumbar, dolor irradiado al testículo).

\section{Cólico renal}

Ocasionalmente los cálculos migran causando el cólico renal. Este síndrome se caracteriza por dolor de comienzo súbito sin un evento precipitante, localizándose en la zona lumbar con irradiación al abdomen (especialmente al flanco) y a la ingle.Se puede extender hasta los testículos, pene y labios mayores de la vagina, siguiendo el recorrido del nervio genitocrural. La extensión del miembro inferior produce aumento del dolor por la contracción del músculo psoas sobre el nervio. El dolor es intenso y cinético: el paciente se mueve constantemente no pudiendo encontrar una postura para calmar el dolor.Puede acompañarse de hematuria, polaquiuria, urgencia miccional o disuria. Con excepción de las nauseas y vómitos secundarios a la estimulación del plexo celíaco, los síntomas gastrointestinales están ausentes.Pueden aparecer fiebre y escalofríos. El dolor se debe a la dilatación del uréter y la pelvis por encima del obstáculo.No es el movimiento del cálculo con la contracción del músculo liso la que provoca el dolor, sino el fracaso de su movilidad, su enclavamiento y la dilatación pieloureteral. El alivio se logra al expulsarlo.

El examen físico es útil para descartar entidades en el diagnóstico diferencial de abdomen agudo:procesos testiculares, ginecológi$\cos$, tumores renales y ureterales. Puede encontrarse puñopercusión lumbar positiva y puntos ureterales dolorosos.

El examen de orina completa debe realizarse en todo paciente. La microhematuria está presente en el $90 \%$, aunque su ausencia no descarta el diagnóstico de litiasis.La observación de una discreta piuria es una respuesta a la irritación por el pasaje del cálculo, no siendo un signo de infección. Es impor tante, además, valorar el $\mathrm{pH}$, la presencia de cristales en la orina y eventualmente algún parámetro de la función renal.

Los estudios por imágenes son esenciales para confirmar el tamaño y localizar el cálculo (ver cuadro 1).El $15 \%$ de los pacientes presentan cálculos bilaterales.

Cuadro 1: Sensibilidad y especificidad para la detección de cálculos renales de los distintos métodos diagnósticos disponibles en la actualidad.

\begin{tabular}{ll|l}
\hline Cálculos ureterales & Sensibilidad & Especificidad \\
\hline Ecografía(signos directos) & $19 \%$ & $97 \%$ \\
\hline Radiografía & 45 a 59\% & 71 a $77 \%$ \\
\hline Urograma excretor con contraste & 64 a $87 \%$ & $93 \%$ \\
\hline Tomografía helicoidal sin contraste & 95 a 100\% & $95 \%$ \\
\hline
\end{tabular}

En las radiografías de abdomen y las del árbol urinario (se prefiere esta última) se visualizan los cálculos con calcio, siendo en general radioopacos y menores a $2 \mathrm{~cm}$. Los de estruvita son algo radioopacos, mientras que los de cistina y los de ácido úrico son radiolúcidos y por lo tanto invisibles radiográficamente. Aún los cálculos radioopacos pueden no visualizarse por interposición con materia fecal, gas o tejido óseo. Otras opacidades no urológicas que obligan al diagnóstico diferencial son los ganglios linfáticos calcificados, la litiasis vesicular y los flebolitos (venas pélvicas calcificadas).

Aunque la ecografía es altamente sensible para detectar hidronefrosis, es muy limitada para visualizar los cálculos ureterales. Per- 
mite el diagnóstico diferencial con patologías renales y ginecológicas, siendo de gran utilidad en embarazadas, anúricos y alérgicos al yodo.

El urograma excretor (UE) ha sido considerado la prueba de referencia. Provee información sobre el tamaño, localización, densidad y grado de obstrucción de los cálculos.Además permite conocer anormalidades anatómicas y funcionales de ambos riñones. Se requiere una buena preparación intestinal y una adecuada hidratación, lo que limita su utilización en pacientes con cólico renal. Es menos sensible en las obstrucciones de alto grado y en algunos litos radiolúcidos que no generan un defecto de llenado. Aunque una creatinina de $1,5 \mathrm{mg} / \mathrm{dL}$ no es una contraindicación absoluta, deben balancearse los riesgos y beneficios. En pacientes diabéticos con metformina se han reportado cuadros de acidosis metabólica fatal luego de procedimientos con contraste endovenoso, por lo que se aconseja suspender la metformina antes del procedimiento y por espacio de 48 horas posteriores al mismo, evaluando la creatinina antes de reiniciar la droga.

La tomografía computada helicoidal sin contraste es más sensible y específica que el urograma excretor y en el futuro probablemente será la técnica de elección. Esta modalidad identifica todos los tipos de cálculos en las distintas localizaciones.

\section{Manejo del cólico renal}

El primer paso es descartar las situaciones que requieren consulta urológica (ver figura 1).La mejor opción analgésica consiste en la utilización de un antiinflamatorio no esteroide (AINE) como diclofenac, ibuprofeno o ketorolac junto a un narcótico (ej. codeína, morfina, meperidina). Además del efecto analgésico, los AINE disminuyen el flujo renal y la producción de orina. La elección de la vía de administración depende de la intensidad del dolor, aunque en la guardia externa la vía endovenosa es la más utilizada por su rápido comienzo de acción. No se recomienda expandir con soluciones endovenosas a los pacientes en la etapa aguda porque puede dilatar aún más la pelvis renal generando más dolor. Los AINE con efecto inhibitorio de la ciclooxigenasa 2 no alteran la función plaquetaria y pueden utilizarse en los días previos a la litotripsia, si bien a la fecha no hay reportes que sustenten su eficacia. Las medicaciones espasmolíticas (propinoxato, escopolamina) no tienen un rol definido y su efectividad no ha sido demostrada.

Figura 1: Manejo inicial de los pacientes con urolitiasis.

\section{CALOLLO OONFRMADO}

$\downarrow$

UROSEPSIS

ANURIA

INSUACIENCIARENAL

$\downarrow$

DOLOR RERACTARIO

NAUSEAS REFRACTARIAS

DAD EXTREMA

CONDICIONES DEBILITANTES $\downarrow$

CALCULOURETERAL

Más de $5 \mathrm{~mm}$

$\downarrow$

CALOULOURETERAL

Menos de $5 \mathrm{~mm}$

\begin{tabular}{|c|}
\hline $\begin{array}{l}\text { INTERCONSULT/ } \\
\text { UROLOGICA } \\
\text { URGENTE }\end{array}$ \\
\hline $\begin{array}{l}\text { INIERCONSULT } \\
\text { UROLOGICA }\end{array}$ \\
\hline DERIVACIONA \\
\hline UROLOGIA \\
\hline TRATAM \\
\hline $\begin{array}{l}\text { CONSERVADC } \\
\text { POR } 4 \text { SEMAN }\end{array}$ \\
\hline
\end{tabular}

La posibilidad de eliminar un cálculo ureteral está en directa relación con el tamaño. Los inferiores a $5 \mathrm{~mm}$ generalmente son eliminados espontáneamente, recomendándose controlar al paciente cada una a dos semanas con algún estudio por imagen.Debe realizarse la consulta urológica si el lito es mayor a $5 \mathrm{~mm}$ o no ha descendido luego de dos a cuatro semanas.

\section{ESTUDIO INICIAL EN UN PACIENTE CON LITIASIS}

En todos los pacientes, aún aquellos con clínica sugestiva pero con imágenes negativas, muchos expertos recomiendan realizar, al menos, una evaluación básica. La evaluación completa se reserva para aquellos pacientes con cálculos que crecen en tamaño, aumentan su cantidad o recurren, así como en los niños o adolescentes con litiasis y en los pacientes que presentan cálculos no compuestos por oxalato de calcio.

\section{Evaluación básica}

\section{Interrogatorio}

Descartar las causas sistémicas asociadas que se describen en el cuadro 3.

Cuadro 3:Valores en orina de 24 horas que definen entidades metabólicas.

Para asegurarse de la exactitud de la recolección, la creatinina urinaria debe ser en las mujeres mayor a $10 \mathrm{mg} / \mathrm{kg} / \mathrm{día}$ y en los varones mayor a $15 \mathrm{mg} / \mathrm{kg} /$ día.

\begin{tabular}{ll}
\hline Hipercalciuria definida & $\begin{array}{l}\text { Mayor o igual a 300mg en varones. } \\
\text { Mayor o igual a 250mg en mujeres. }\end{array}$ \\
\hline Hipercalciuria marginal & Entre 140 y $300 \mathrm{mg}$ en varones. \\
& Entre 140 y $250 \mathrm{mg}$ en mujeres. \\
\hline Hiperfosfaturia & Mayor a 1100mg. \\
\hline Hiperuricosuria & Mayor a 800mg en el varón. \\
& Mayor a 750mg en la mujer. \\
\hline Hiperoxaluria & Mayor a 40mg. \\
\hline Hipocitraturia & Menor a 320mg. \\
\hline Hipomagnesiuria & Menor a 70mg. \\
\hline Cistinuria & Se determina cualitativamente.
\end{tabular}

Excluir los fármacos que contribuyen a la formación de cálculos: hipercalciuria (diuréticos de asa, glucocorticoides, vitamina $D$ y teofilina), antiácidos con calcio (pueden alcalinizar la orina incrementando la carga filtrada de calcio precipitando el fosfato de calcio), acetazolamida (genera una acidosis metabólica que promueve la resorción ósea de calcio, alcaliniza la orina y disminuye el citrato ur inario), tiazidas (reducen la calciuria pero provocan uricosuria), allopurinol (puede provocar cálculos al aumentar la excreción de xantinas), tr iamtireno, aciclovir e indinavir (los mismos fármacos pueden precipitar).

Investigar causas de origen hereditario: la herencia de la hipercalciuria idiopática puede ser autosómica dominante; sospechar en los niños el diagnóstico de hiperoxaluria primaria y de cistinuria (ambas de herencia autosómica receciva).

Respecto de la dieta recordamos que no todos los líquidos son útiles para prevenir los cálculos.El té tiene oxalatos y puede contribuir a la hiperoxaluria, mientras que el café y ciertas gaseosas contienen cafeína, que producen una leve depleción de volumen por su efecto diurético. Debe, además, interrogarse sobre la ingesta de proteínas animales, purinas, comidas ricas en sodio y oxalatos.

\section{Examen físico}

El examen físico suele ser normal. En algunos casos revela la presencia de alguna enfermedad sistémica: los tofos gotosos orientan a hiperuricosuria, las fístulas enterocutáneas a enfermedad de Crohn. Los pacientes inmovilizados pueden desarrollar hipercalciuria y que el sondaje vesical crónico puede asociarse con infecciones y cálculos de estruvita.

\section{Estudios complementarios}

La orina completa permite observar hematuria cuando existe enfermedad activa. Si la densidad urinaria es elevada uno puede pre- 
sumir la falta de hidratación. Los pacientes con cálculos de ácido úrico suelen tener un $\mathrm{pH}$ urinario inferior a 6 , mientras que los $\mathrm{pH}$ urinarios elevados pueden originarse en la acidosis tubular distal. El urocultivo se solicita si existe alguna evidencia de infección en el análisis de orina.

Se recomienda dosar en sangre calcio, fósforo, ácido úrico, sodio, potasio, cloro, bicarbonato y creatinina, debiéndose descartar hiperparatiroidismo frente a hipercalcemias con o sin hipofosfatemia o en pacientes con calcio normal/alto que se repite en más de una medición. Un bajo bicarbonato sérico puede hacer pensar en una acidosis tubular distal.

Todos los pacientes deben ser evaluados por algún estudio por imágenes a través de una radiografía de árbol urinario y ecografía (generalmente suficientes) o bien con urograma excretor o tomografía helicoidal cuando queden dudas.

Es importante hacer un estudio fisicoquímico del cálculo si pudo ser rescatado, aunque no necesariamente revela las alteraciones metabólicas del paciente.

El cuadro 2 resume las etapas de la evaluación básica de los pacientes con litiasis urinaria.

Cuadro 2:Etapas de la evaluación básica.

\section{Anamnesis}

- Descartar causas sistémicas, excluir fármacos, investigar causas de origen hereditario, interrogar sobre dieta e ingesta hídrica.

\section{Examen físico \\ - Tofos gotosos, fístulas enterocutáneas, inmovilidad, presencia de} sonda vesical.

\section{Estudios complementarios}

- Orina completa y niveles de calcio, fósforo, ácido úrico, sodio, potasio, cloro, creatinina en sangre.

- Evaluación de imágenes.

- Estudio fisicoquímico del cálculo renal.

- Urocultivo.

- Rastreo urinario de cistina.

\section{Evaluación completa}

Además de realizarse todo lo descripto en la evaluación básica se procede a efectuar el estudio metabólico de litiasis renal. Durante siete días consecutivos se realiza una dieta sin lácteos ni derivados, ni alimentos salados. Se debe ingerir al menos dos litros de líquido y un gramo de calcio por día, realizándose mediciones repetidas en sangre y orina de 24 horas. Estos estudios no deben llevarse a cabo dentro de las cuatro semanas de la obstrucción o de la remoción del cálculo, ya que los síntomas relacionados al cólico renal o al trauma del parénquima renal pueden alterar la medición. La orina de 24 horas servirá para medir el volumen, calcio, oxalato, sodio, fósforo, ácido úrico, citrato y creatinina.También se medirá el pH en una muestra aislada.

Del estudio metabólico surge el diagnóstico etiológico en el $85 \%$ de los casos, recomendándose repetir el mismo en los pacientes con estudios negativos.

\section{TRATAMIENTO NO ESPECÍFICO}

Las intervenciones no farmacológicas son bastante efectivas y reducen la incidencia de litiasis recurrente a los cinco años en aproximadamente un $60 \%$.

El incremento de fluidos aumenta el flujo urinario. Si bien no hay estudios clínicos controlados, sigue siendo una recomendación lograr un volumen urinario mayor a dos litros por día, lo que implica una ingesta hídrica de 2,5 litros por día.

Debe reducirse el aporte proteico de la dieta a 0,8 a 1 $\mathrm{g} / \mathrm{kg} /$ día para desincentivar el aumento de la calciuria por el mecanismo ya ex- plicado y para evitar la acidosis metabólica, que estimula la reabsorción renal de citrato y facilita la precipitación de cristales de ácido úrico.

A mayor ingesta de sodio hay menor reabsorción de calcio en los túbulos renales. Una dieta baja en sodio (2 a $3 \mathrm{~g} /$ día) reduce la excreción de calcio en personas normales y en pacientes con hipercalciurias. El sodio en orina de 24 horas permite evaluar si el paciente cumple con las normas dietarias sugeridas.

No está indicada una disminución en la ingesta de calcio porque aumenta la excreción urinaria de oxalato por falta de fijación a nivel intestinal.Los pacientes con dietas normocálcicas tienen menos cálculos que aquellos con restricciones dietarias.

Aunque la evidencia es limitada se debe evitar el consumo excesivo de vitamina $\mathrm{C}$, ya que el ácido oxálico es un producto de su metabolismo. En pacientes con patología recurrente se debe reducir los alimentos ricos en oxalato: manzana, naranja, ananá, cerveza, queso, leche, yogurt, cocoa, chocolate, bebidas cola, café, te, nueces, espinaca, brócoli y maní.

Una forma de aumentar el citrato urinario consiste en ingerir limonadas.

\section{ENTIDADES NOSOLOGICAS Y TRATAMIENTO ESPECÍFICO}

En el cuadro 3 se describen los valores de excreción urinaria de 24 horas que definen entidades metabólicos y en el cuadro 4, los principales trastornos y sus causas.

Cuadro 4: Principales trastornos metabólicos y sus causas.

\begin{tabular}{|c|c|}
\hline Hipercalciuria idiopática renal & $29 \%$ \\
\hline Hipercalciuria idiopática absortiva & $27 \%$ \\
\hline Hipercalciuria secundaria & $03 \%$ \\
\hline \multicolumn{2}{|l|}{ Hiperparatiroidismo primario } \\
\hline \multicolumn{2}{|l|}{ Acidosis tubular renal distal } \\
\hline \multicolumn{2}{|l|}{ Inmovilizació } \\
\hline \multicolumn{2}{|l|}{ Enfermedad de Paget } \\
\hline \multicolumn{2}{|l|}{ Sarcoidosis } \\
\hline \multicolumn{2}{|l|}{ Hipertiroidismo } \\
\hline \multicolumn{2}{|l|}{ aushing } \\
\hline \multicolumn{2}{|l|}{ Intoxicación con vitamina D } \\
\hline \multicolumn{2}{|l|}{ Exceso de cal cio } \\
\hline Hiperuricosuria y/o hiperuricemia & $14 \%$ \\
\hline \multicolumn{2}{|l|}{ Gota } \\
\hline \multicolumn{2}{|l|}{ Síndromes mieloproliferativos } \\
\hline \multicolumn{2}{|l|}{ Anemia hemolítica } \\
\hline \multicolumn{2}{|l|}{ Síndrome de lisis tumoral } \\
\hline \multicolumn{2}{|l|}{ Farmacológicas } \\
\hline \multicolumn{2}{|l|}{ Dietas ricas en purinas } \\
\hline Hipercalciuria y/o hiperuricemia y/o hiperuricosuria & $14 \%$ \\
\hline Hiperoxaluria & $0,4 \%$ \\
\hline \multicolumn{2}{|l|}{ Dieta hiperoxalúrica } \\
\hline \multicolumn{2}{|l|}{ Hiperoxaluria primaria } \\
\hline \multicolumn{2}{|l|}{$\begin{array}{l}\text { Oxaluria entérica: enfermedad de Crohn, } \\
\text { pancreatitis, obstrucción biliar. }\end{array}$} \\
\hline pH urinario elevado & $2 \%$ \\
\hline \multicolumn{2}{|l|}{ Acidosis tubular renal distal } \\
\hline \multicolumn{2}{|l|}{ Exceso de álcalis } \\
\hline \multicolumn{2}{|l|}{ Infecciones urinarias } \\
\hline Hipocitraturia & $1 \%$ \\
\hline \multicolumn{2}{|l|}{ Acidosis tubular renal distal } \\
\hline \multicolumn{2}{|l|}{ Enfermedad intestinal } \\
\hline \multicolumn{2}{|l|}{ Deficiencia dietaria } \\
\hline Hipomagnesiuria & $9,5 \%$ \\
\hline Cistinuria & $0,25 \%$ \\
\hline
\end{tabular}

\section{Cálculos de oxalato de calcio}

El $90 \%$ de los cálculos de oxalato de calcio son idiopáticos y se asocian a alguna de las siguientes anormalidades metabólicas: hipercalciuria, hiperuricosuria, hipocitraturia o hiperoxaluria, siendo la hipercalciuria la anormalidad metabólica más frecuente (está presente en el 40 al $60 \%$ de los pacientes con litiasis cálcicas). 
La alteración primaria de la hipercalciuria renal idiopática es una disminución en la reabsorción tubular distal de calcio que reduce su concentración plasmática, estimulando la secreción de parathormona, que aumenta la síntesis renal de $1,25(\mathrm{OH})$ vitamina D. Así se mantiene la calcemia a expensas de la absorción intestinal y la resorción ósea. Puede tratarse con diuréticos tiazídicos, que aumentan la reabsorción tubular distal de calcio. Como la hipokalemia reduce la excreción de citrato, a veces es preferible combinarlos con un ahorrador de potasio (amiloride) o bien aportar citrato de potasio. El exceso en la dieta de cloruro de sodio provoca una pérdida en la efectividad de estos diuréticos, incrementando además la excreción de calcio.

Los pacientes con hipercalciuria idiopática absortiva presentan un defecto primario a nivel del yeyuno en donde existe hipersensibilidad de los receptores a la vitamina D.La hipercalciuria sobreviene por el aumento de la carga filtrada y la disminución de la reabsorción tubular distal debido a la supresión de la hormona paratiroidea. El calcio sérico es normal puesto que la pérdida renal es compensada por el aumento en la absorción intestinal. El tratamiento se basa en el uso de resinas de intercambio iónico no absorbibles que se unen al calcio e inhiben su absorción. En casos de respuesta deficiente se agregan tiazidas.

Dentro de las causas secundarias de hipercalciuria, la más frecuente es el hiperparatiroidismo primario. El $50 \%$ de los pacientes con hiperparatiroidismo primario se diagnostican a partir del hallazgo de un cálculo renal. El aumento de la parathormona incrementa la resorción ósea y aumenta la síntesis de 1,25 (OH) vitamina $\mathrm{D}$, aumentando el calcio plasmático.Frente a calcemias elevadas o en el límite superior de lo normal debe solicitarse un dosaje de parathormona (PTH). El tratamiento es quirúrgico. Como diagnóstico diferencial de litiasis e hipercalcemia se encuentran la sarcoidosis, el mieloma, la intoxicación con vitamina D y el hipertiroidismo.

La hiperuricosuria está asociada con el núcleo de ácido úrico sobre el que se deposita el oxalato de calcio. El 15\% de las litiasis cálcicas tienen hiperuricosuria. El tratamiento consiste en restringir las purinas y reducir la excreción renal de ácido úrico con allopurinol.

La hipocitraturia se observa en enfermedades intestinales, déficit dietarios y acidosis tubular renal distal. Se tratan con citrato de potasio.

El oxalato es el producto final del metabolismo del ácido ascórbico, del glicoxalato y de productos exógenos como el etilenglicol. Los niveles de oxalato solo están levemente aumentados en los pacientes con litiasis cálcica idiopática.La importancia clínica de este hallazgo no es clara, al igual que el tratamiento, que consiste en reducir el exceso de oxalato de la dieta.La oxaluria entérica es la causa más frecuente por malabsorción del intestino delgado (enfermedad de Crohn, bypass yeyuno-ileal, pancreatitis crónica y obstrucción biliar). En estos casos el exceso de sales biliares y ácidos grasos fijan calcio, no pudiendo quelarse así el oxalato. Además presentan diarrea malabsortiva que reduce el volumen
urinario.El tratamiento consiste en controlar la enfermedad de base y una dieta pobre en grasas-oxalatos y rica en calcio.

La hipomagnesiuria se observa como defecto metabólico en el $9,5 \%$ de los casos, siendo el tratamiento el aporte de magnesio oral.

\section{Cálculos de ácido úrico}

El ácido úrico es el producto final del metabolismo de las purinas. Las fuentes principales en la dieta son el hígado, el riñón, el corazón, los mariscos, los extractos de carne, etc.Los cálculos de ácido úrico se forman en orinas persistentemente ácidas ( $\mathrm{pH}$ menor a 5,5) y/o cuando aumenta la excreción de ácido úrico.

El $20 \%$ de los pacientes gotosos son hiperuricosúricos y forman cálculos. Otras causas son el aumento del recambio celular (anemia hemolítica, desórdenes mieloproliferativos, síndrome de lisis tumoral) y los fármacos uricosúricos (salicilatos, tiazidas y probenecid).

El tratamiento inicial es llevar la orina a un $\mathrm{pH}$ de 6,5 con citrato de potasio.Completan la terapéutica el allopurinol (100 a 300mg/día) y la reducción en la ingesta de purinas.

\section{Cálculos infectados (estruvita)}

Pueden ser de gran tamaño y emitir ramificaciones a la pelvis y a los cálices renales. De allí el nombre de cálculos coraliformes o en astas de ciervo.

Los gérmenes desdoblan la urea en anhídrido carbónico y amonía$\mathrm{co}$, que se convierten en bicarbonato y amonio respectivamente. El fosfato urinario (buffer) se combina con el amonio tomando magnesio libre. Este compuesto (fosfato-amonio-magnesio) es de fácil e inmediata precipitación.

Los gérmenes más frecuentes que desdoblan la urea son Proteus, Klebsiella y Pseudomona (la E.Coli no desdobla la urea).La mayoría de estos pacientes presentan drenaje urinario anormal que favorece las infecciones del tracto urinario.

El tratamiento consiste antibióticos y en la remoción completa del cálculo.

\section{Cálculos de cistina}

Ocurren en pacientes con cistinuria.Este desorden hereditario autosómico recesivo se caracteriza por un defecto en el sistema de transporte de membrana de los aminoácidos básicos, tanto en el túbulo proximal renal como en el tracto gastrointestinal. Es más frecuente en la mujer en la segunda o tercera década de la vida. El tratamiento médico consiste en reducir la concentración de cistina urinaria con hidratación, en incrementar la solubilidad de la cisitina con alcalinización y en disminuir la cistina urinaria con d-penicilamina o alfa-mercaptopropilmicina.

\section{ROL DE LA LITOTRIPSIA}

La litotripsia utiliza ondas de choque para fragmentar los cálculos renales.De esta forma facilita su migración a través del uréter. Es efectiva para remover cálculos renales no infectados o complicados menores a $2 \mathrm{~cm}$ de diámetro. El límite para los cálculos en el polo inferior del cáliz renal y en el uréter es de $1 \mathrm{~cm}$.

En los cálculos ureterales del tercio inferior se prefieren las técnicas endoscópicas.

\section{Dr. Alejandro Abbate}

[ Profesor Asistente y Coordinador de la Carrera de Especialización y Residencia de Medicina Interna - Instituto Universitario CEMIC ]

\section{Bibliografía}

1- Borghi L, Schianchi T, et al. Comparison of two diets for the prevention of recurrent stones in idiopathic hypercalciuria. N Engl J Med 2002;346:77-84

2- Curhan G, Willett WC, et al.A prospective study of dietary calcium and other nutrients and the risk of symptomatic kidney stones.N Engl J Med 1993;328:833-38.

3- Ingelfinger JR.Diet and kidney stones.N Engl J Med 2002;346:74-76.

4- Monk R.Clinical approach to adults litiasis.Seminars in Nephrology 1996;16:375-88.

5- Portis A, Sundaram C.Diagnosis and Initial Management of Kidney Stones.Am Fam Physician 2001;63:1329-38.

6- Prevention and treatment of kidney stones.National Institutes of Health Consensus Development Conference Statement.March 1988.

7- Shuster J.Soft drink consumption and urinary stone recurrence.J Clin Epidemiol 1992; 45:911-6.

7- Shuster J.Soft drink consumption and urinary stone recurrence.J Clin
8- Zanchetta J.Litiasis renal. Biblioteca de Medicina.V-Nefrología.1992 